\title{
Featured Artist
}

\section{M.Srinivasa Rao: the Modern Sculptor}

By Archana Sonti (Artist)

Talent, Skill, Creativity-all in one, makes the Sculptor M.Srinivasa Rao.

Trained in traditional temple sculpture in his early education at Tirupathi and reading the history books on temple sculpture, related mythological stories as part not only of his curriculum but out of his personal interest, contributed to the making of his art.

These mythological characters, images, iconography, symbols, forms still influence Srinivas but he presents these

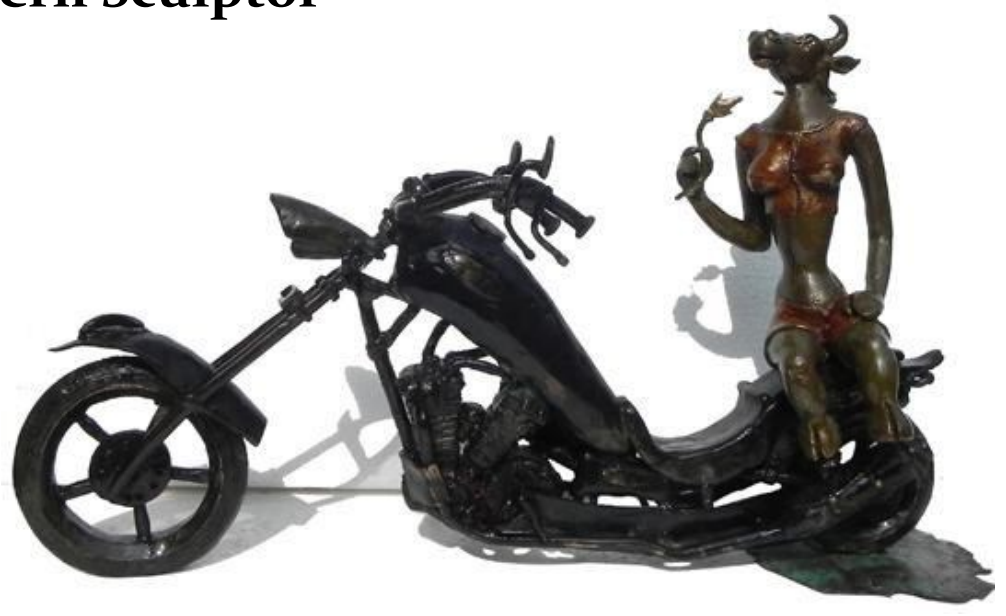

Figure 1 Title-'143'(I Love You), Medium--Bronze, Size-15" x 8" x 5"2011 He says about 143 "in 2011 when I bought Avenger bike quitting Pulsar, while enjoying the bike driving with my wife the concept seeped in and the intervention started."

to express his modern day concepts of

new technology and contemporary city life style amalgamating both and bringing new visual language, sometimes in a conscious effort and Sometimes with a subconscious manner. Traditional sculptures are geometrical and are mathematical but his are free flowing and also negating the detail design aspects of traditional sculptures, he has simplified the form and the lines in his sculptures to bring his own personalized form and concept. He says 'Indian Sculptures and art has always been surrealist, so it has a natural influence in my work.

"If I have not taken admission in BFA or MFA I would have settled as temple sculptor in my home town.

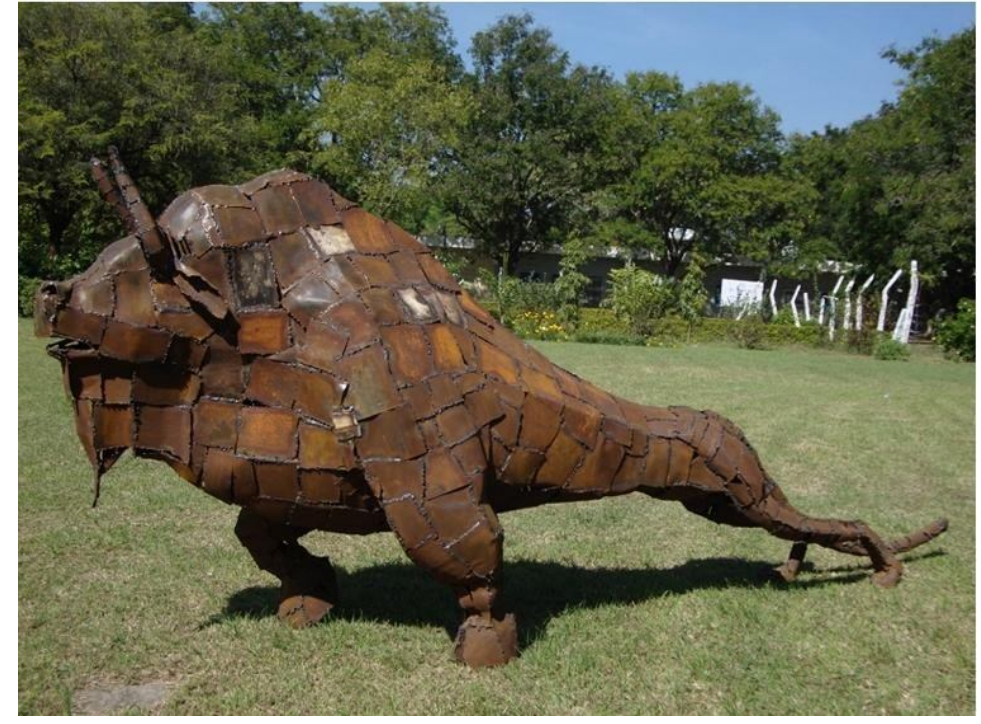

Figure 2. Title- 'bull'-medium- iron scrape size- $210 \mathrm{~cm} \times 150 \mathrm{~cm} \times 120 \mathrm{~cm}$, year - 2009.
My further studies has changed my perspective and taught me new ways of expressions."

In the bison-influenced 'bull form' he treated the form in many ways working with different materials, he tried to simplify the form more and more, the free flowing lines in his sculptures without losing the speed, vigor and the natural character of the animal. He recalls "we have such training that I can draw from top to bottom of the human figure or animal in single line." 


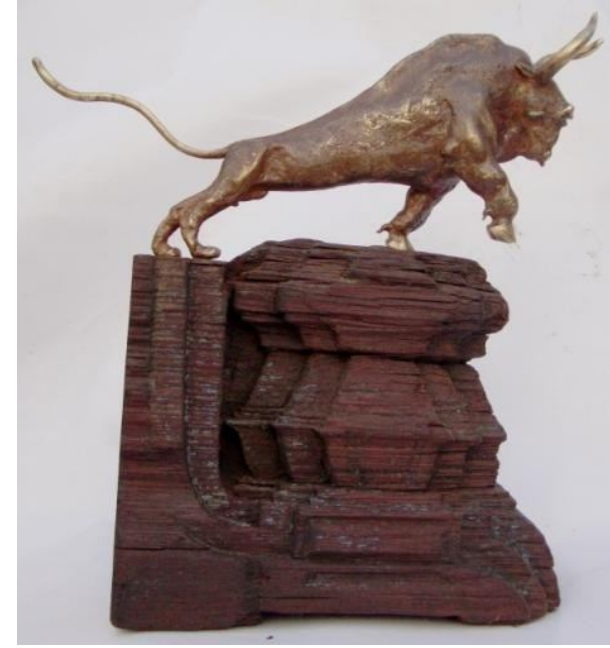

Figure 3. Title- 'Lead' medium-- bronze and

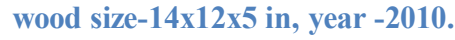

That kind of rhythmic line he tried to bring in the bull form. It's visible how much the sculptor has enjoyed the Play in shaping the form, fine-tuning, and sometimes in complete smoothness and in other he bought roughness through textures and the materials.

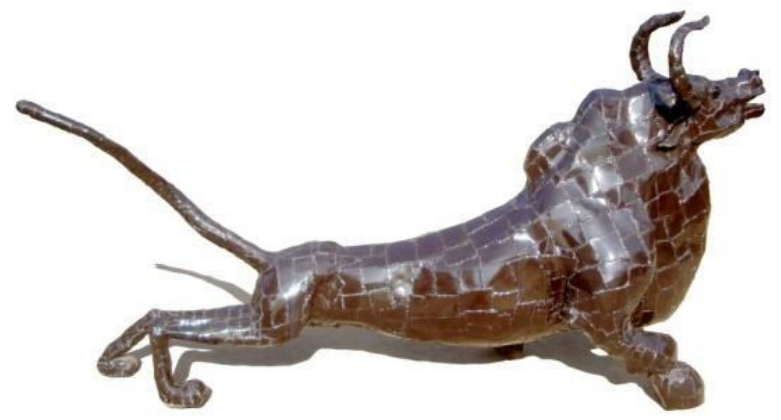

Figure 4. 'bull' Iron 58" 330 "x120".

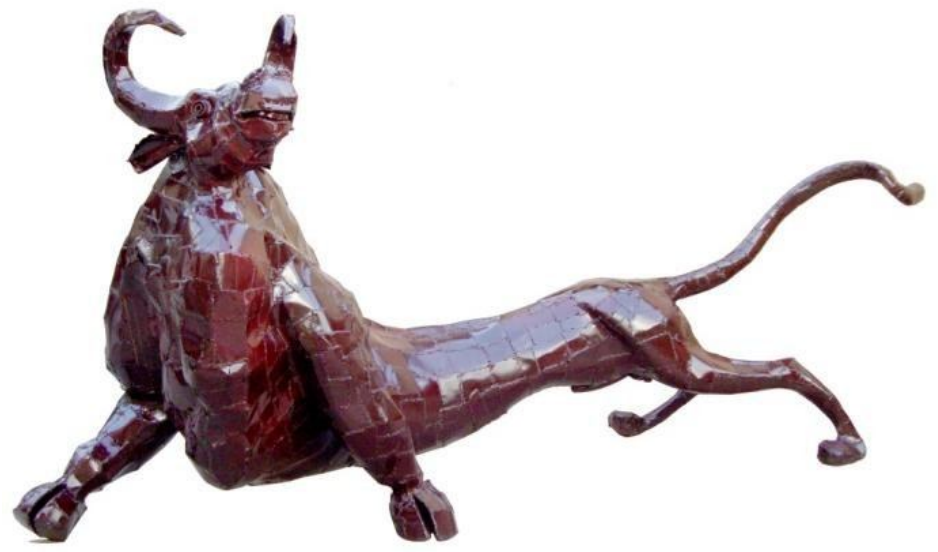

个 Figure 5.

'Bull'- Deco colours on Iron S- $123 \times 54 \times 63$ inches. $\rightarrow$ Figure 6 .

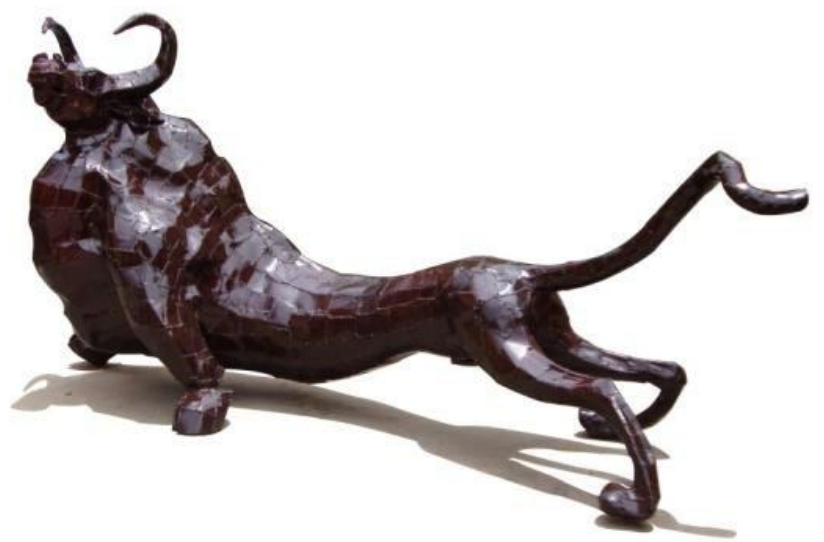




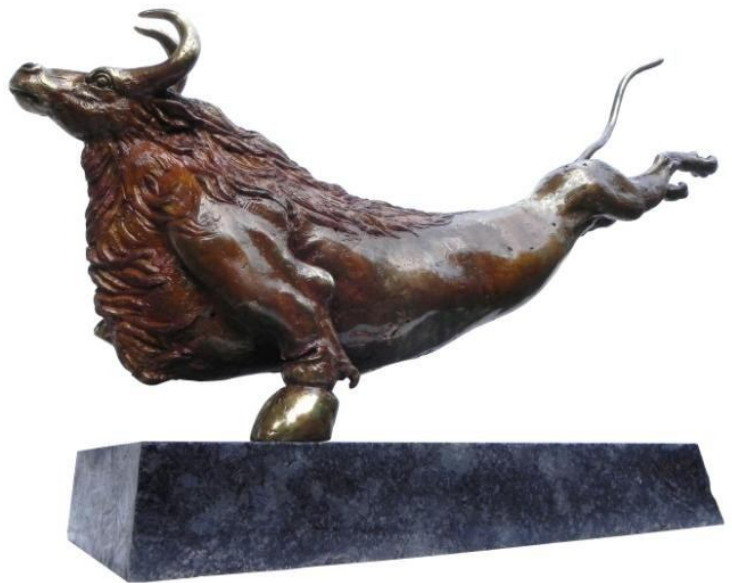

The bike series is still continuing and the bulls resisting to leave; he says "I will do these forms until they leave me by themselves, till then I will work on these forms, every time the form goes to next level of either simplification or some changes, the women series also transforming at every level and I am enjoying every bit of the transformation process."

Figure 7. bronze and stone-12x10x24in.

Figure 8. Size-7x5x10 in, Medium-Bronze, Yr-2011. $\rightarrow$
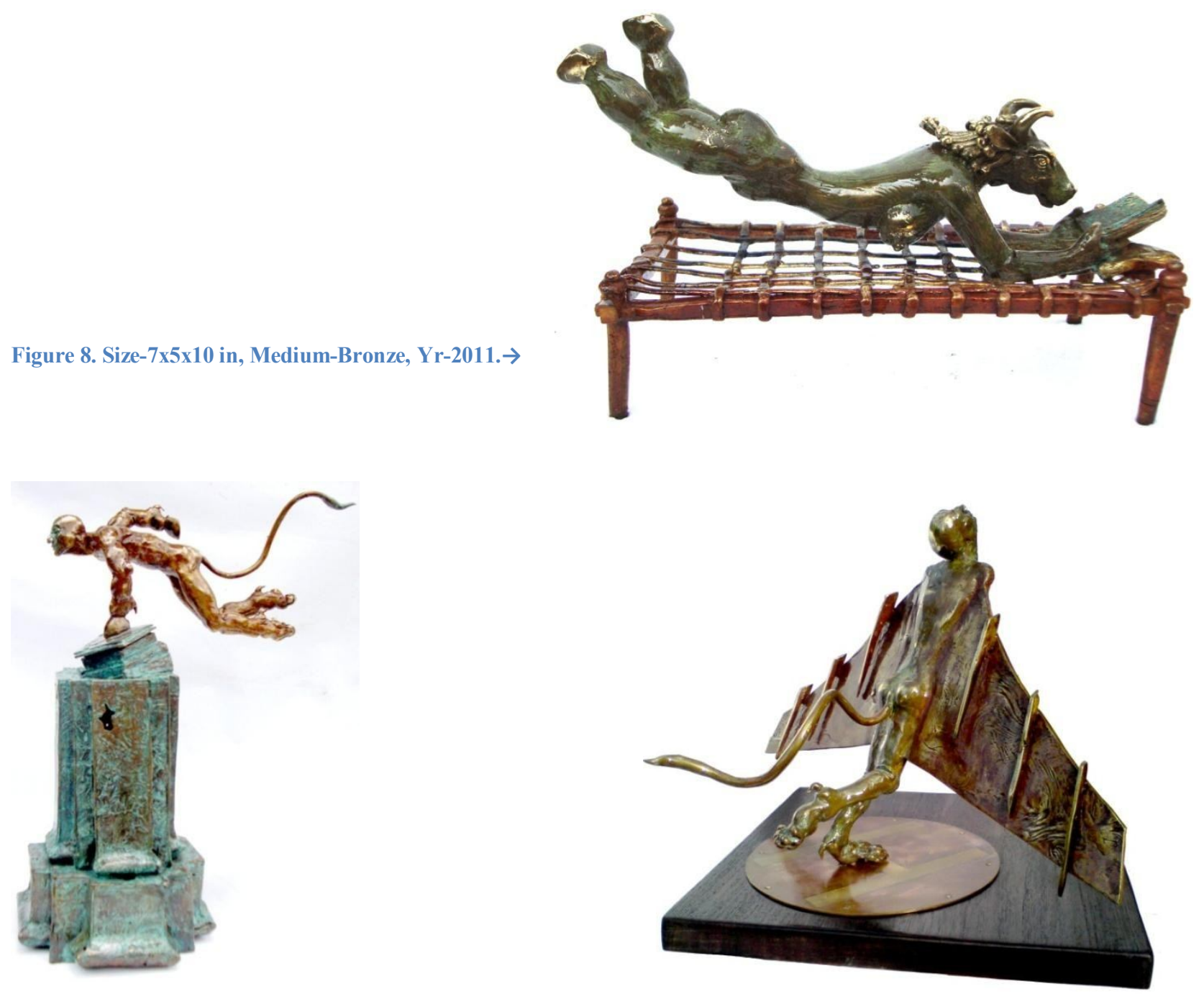

Figure 9. Achiever'-20x9x9 inc, medium-bronze. Year - 2010

Fig.10. Garuda - 'take off' patina on bronze and iron, Size- 16x10x13 inches-2014 个 

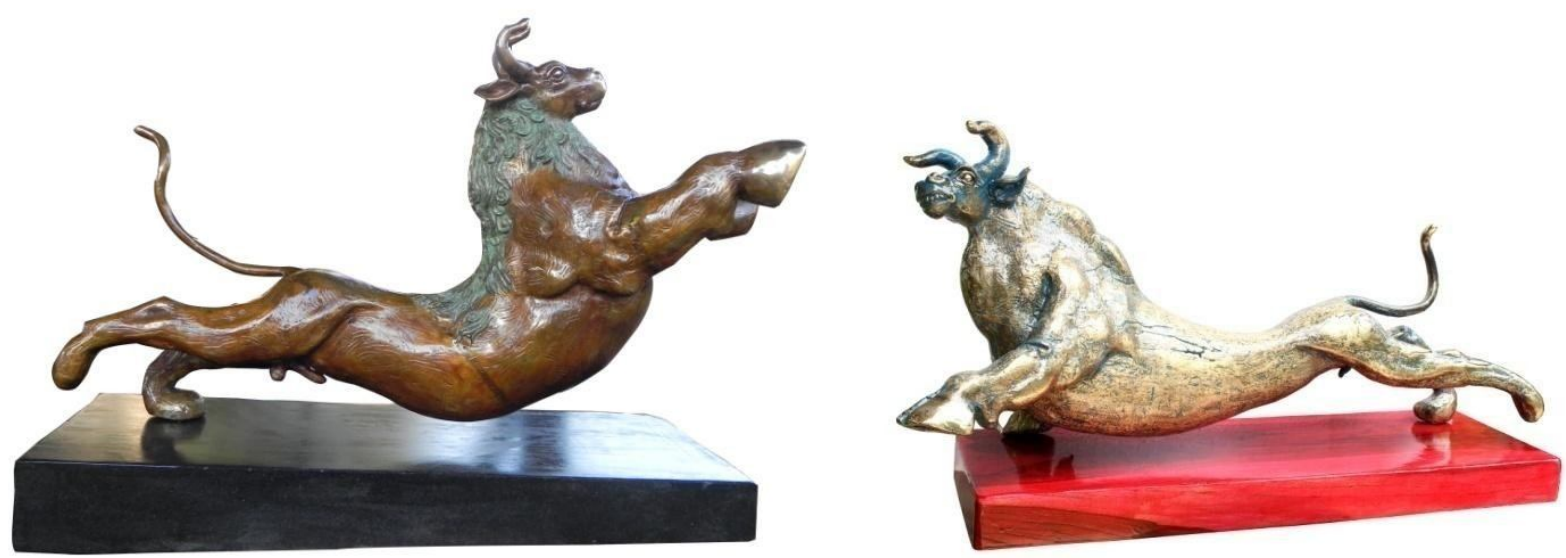

Figure 11.'Bull’, size-17X24X9 inc, medium-Bronze and stone, 2012. $\quad$ Figure.12. Bronze and wood - 29x15x11 inc-2016

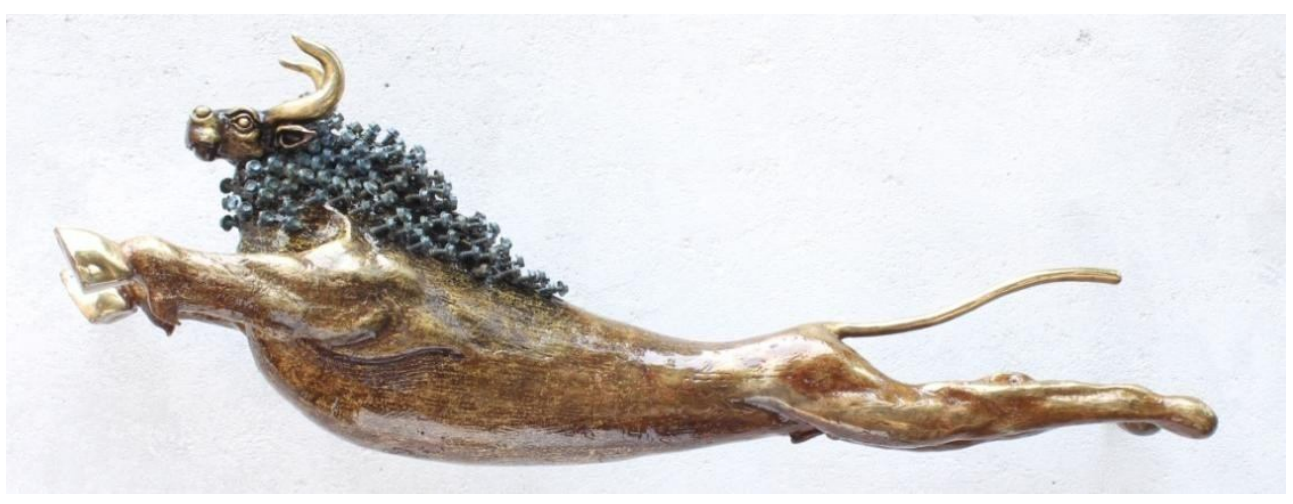

Figure. 13. Material-Bronze and Iron, Size-35x12x10 inches Year -2016. 个

Figure. 14. 'Desire', Bronze, iron, aluminium and stone-8x24x8 inch-2015. $\downarrow$

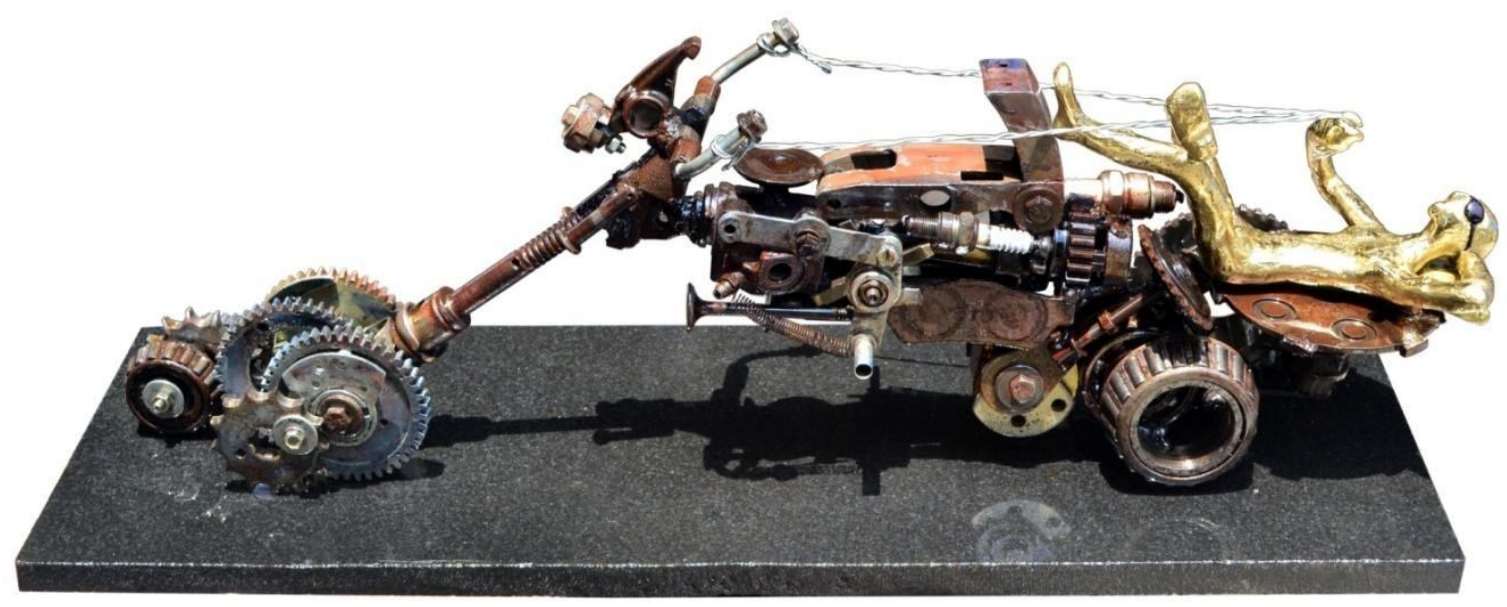



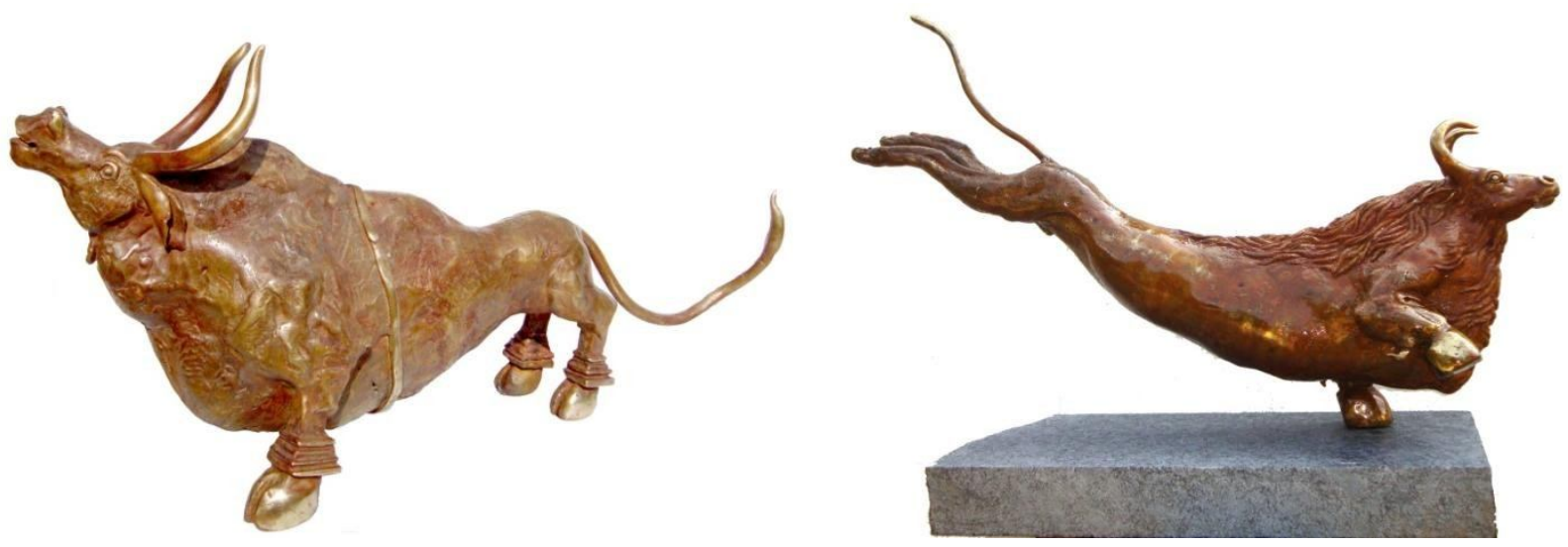

Figure 15. bronze-9x17.5x4 inc-2010. $\downarrow \uparrow$ Sold in India Art Summit. $\uparrow$ Figure.16. 19x28x8 inc-Bronze and stone-2011

In the India Art Fair 2012 show in New Delhi, through Kalakriti Art Gallery, three of his bronze bulls were exhibited and the three of them got sold. He got commission for two more bulls. The viewership and the experience was great, he recalls.

Figure. 17. 'Holly bull' Medium-Bronze, Size-10x24x4 in,2010.

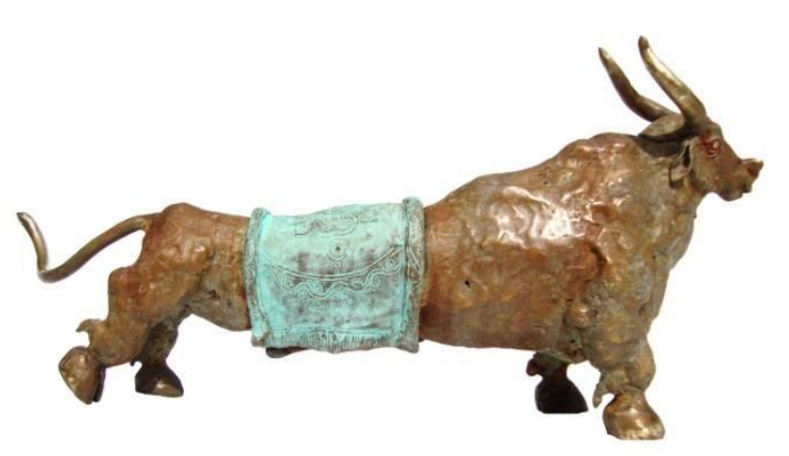

$\leftarrow$ The cloth on the animal body speaks that it is a domesticated animal by human and the static pose, the facial expression reveals that it is a submissive one. 'Holy Bull' is in the context of Indian tradition.

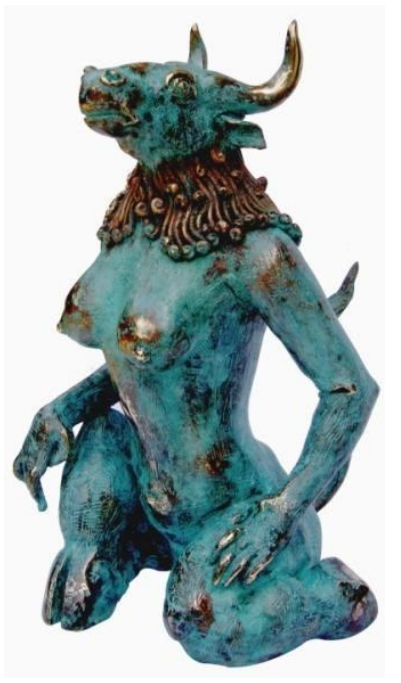

Figure 18. 'bull' medium- Bronze S-10x6x4 in, yr-2010 个

Figure 19-20.'Nayaki', medium- Bronze size-11x6x7.5 In. 


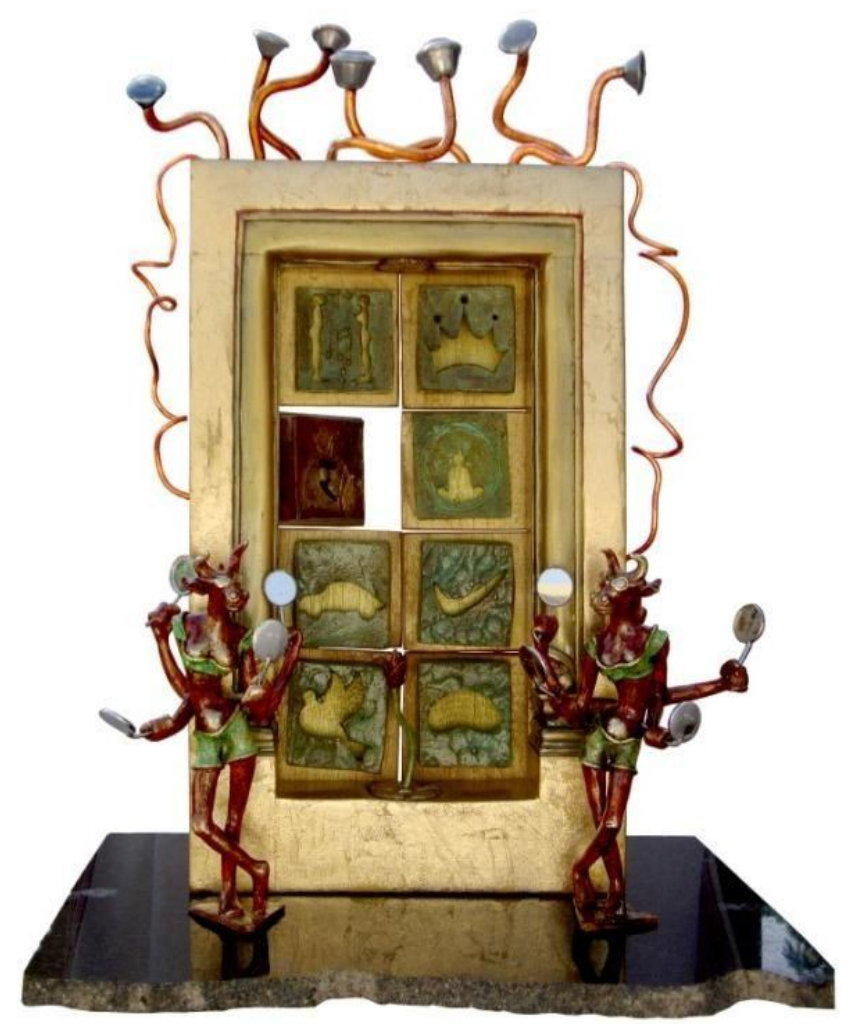

When he saw Rodin's "The Gates of Hell" he thought why gates of hell, why not 'gates of heaven' and thus he changed the concept a bit and done 'Gates of desires'. Gates of desires has a Door with Eight windows and each door opens to basic desires of human like, Man and womanLust, Crown for power, Rupee for Money, Meditation for enlightenment, car for materialist desires, Nike for freedom, Dove for peace, the cloud symbolizes the Sculptor (his dream to become a sculptor). His Super Betty, the urban stylish chicks holding many mirrors in more than two hands are standing at the door, telling that all the windows of the door can be opened one by one when we wish to.

Figure 21. 'Gates of Desires'-wood,bronze,copper,steel ,mirror,gold foil and stone(mixed media) 23x19x13 inch-2015.

Bulls here are 'Dwarapalakas', to secure holy thing which is kept inside the door. A symbolical representation of powerful Gate-keepers

Figure 22. 'Dwarapalakas'

Medium-bronze and wood

Size- $45 \times 20 \times 16$ In,

Year-2010. $\rightarrow$

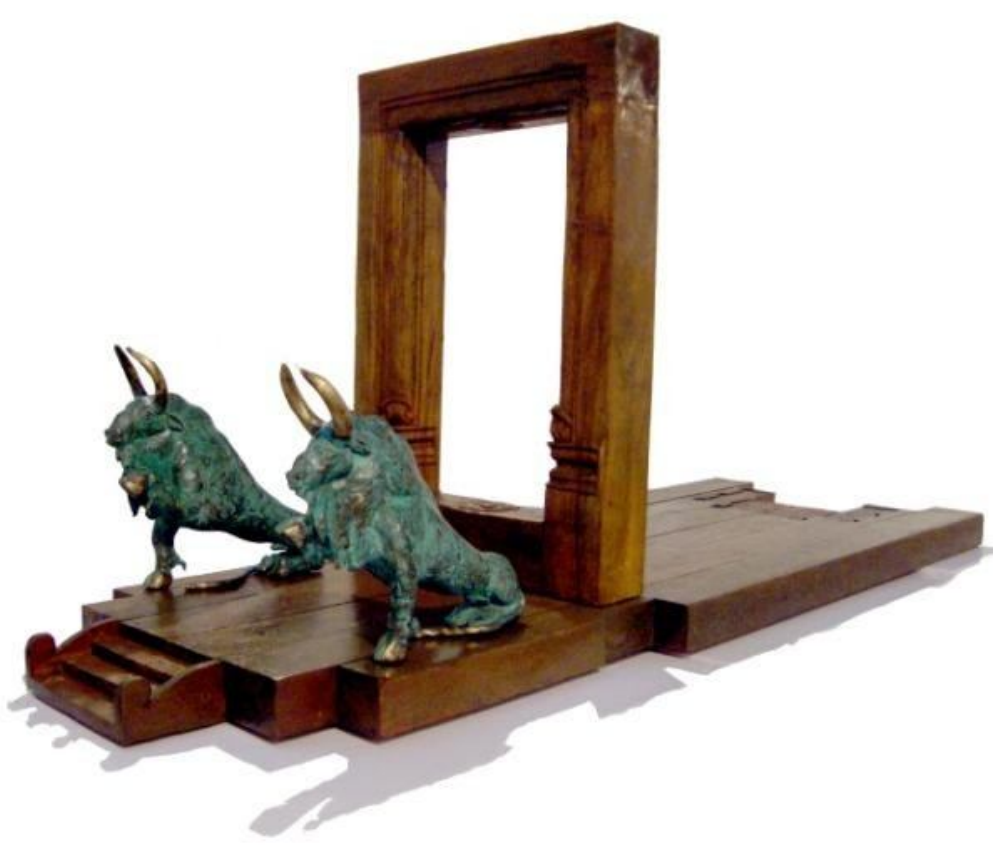




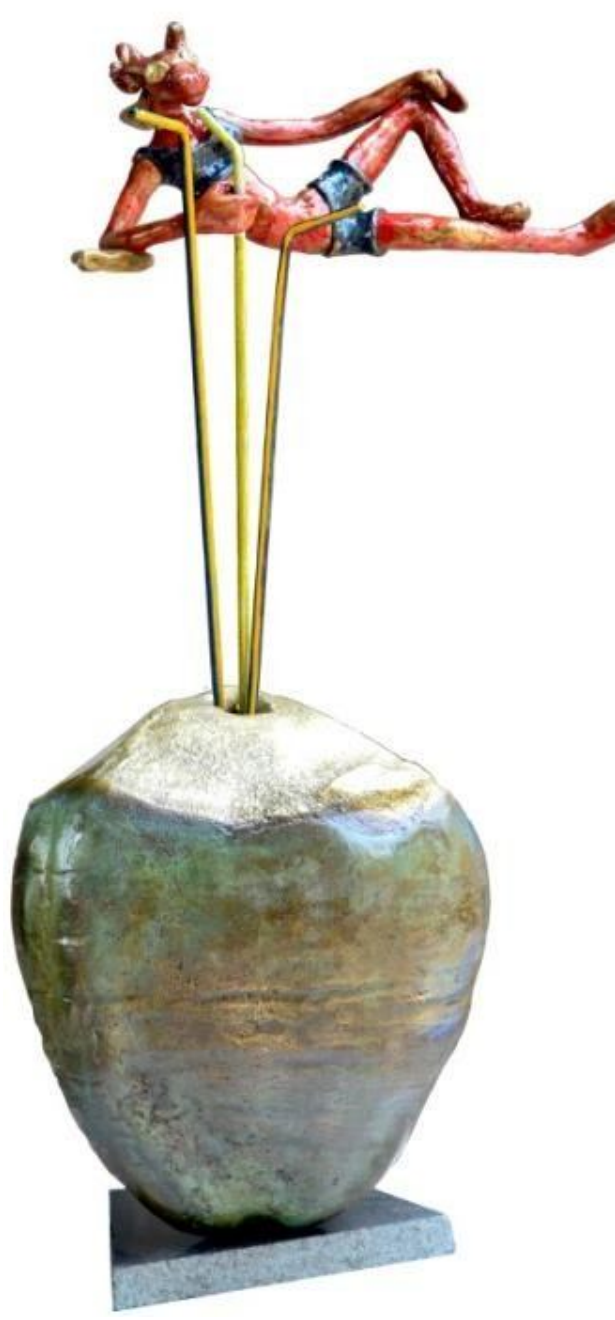

'Three straws' symbolize the physical relationships of woman with more than one man. 2 straws means sexual intercourse between two but when another straw comes in, it means number doesn't matter. The woman will be usually paid. In some villages there is a culture of mixing alcohol in coconut water and offered to women and after the man who offers and the women who takes the offer consume it and they have intercourse, sometimes if another man offers, she takes that too. The coconut water symbolizes purity when it is adulterated with alcohol it loses its natural form. This he has seen in his surrounding villages and that has reflected in the work 'women drinking coconut water with 3 straws'. But keeping the context with symbolic means of using 3 straws, he also tried to transform it into totally different meanings of his modern concepts and treatment. The female figure in the air, the reclining posture, the body Language speaks the freedom she possesses to choose to behave as she feels like, and she makes her decision.

Giving a statement that she only owns authority on her body and total balance of life. The woman challenging the patriarchal social order and breaking the conventional norms of not only sexual life but in all aspects of her life. She holds the power in the universe, to achieve what she desires. 'Who cares, I am the boss of my life' a perfect representation of real strength of a woman.

\section{个 Figure 23-24 $\rightarrow$}

'Three straws'

Medium-Bronze, Iron and stone,

Size-18x10x7 inch

Year-2015

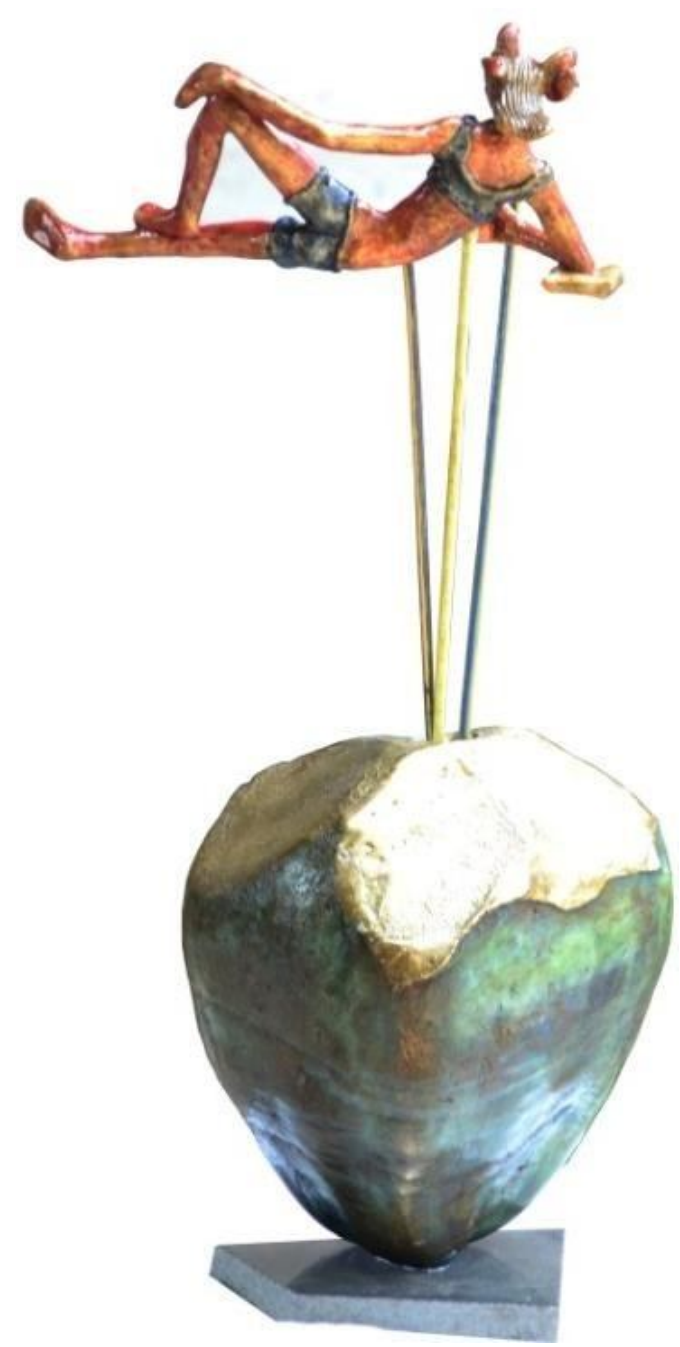




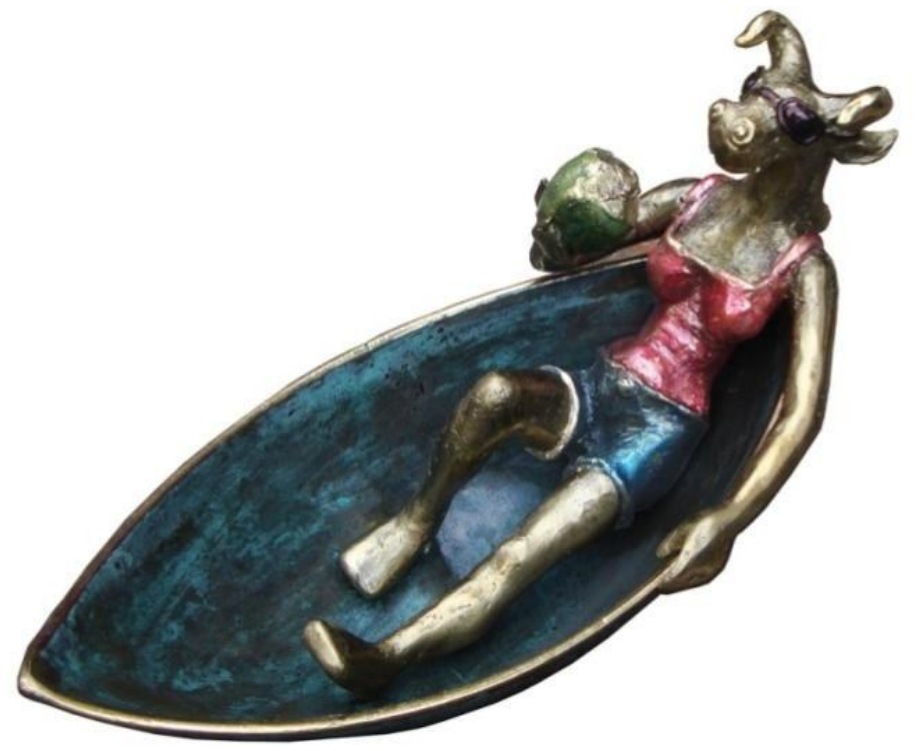

个Figure 25. Title-'cooool', Medium-Bronze, Size-10x6x4 in, Year-2015.

For example, the women with bull head. The women here are pretty contemporary wearing goggles, modern jeans clothes, shoes, lipstick etc and why bull head? He is influenced by yaksha-yakshini concept in traditional sculpture; these characters are with bull head. But for Srinivas bull head represents the women with strength in all aspects.

Mix of traditional and modern not only in concept but the characteristic treatment of form, and a mix of village and city lifestyle is depicted symbolically. His female figure is like a super Betty (Urban stylish chick),

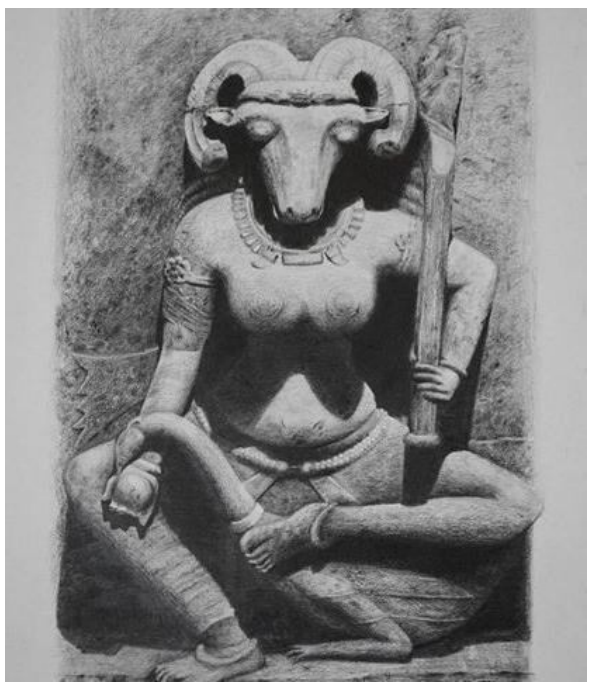

representing women as an epitome of style, confidence modernity and freedom.

Figure 27. Traditional Yakshini sitting on a peacock

Figure 28-29. Acrylic on fiberglass23x15x11 in-- 2013. $\rightarrow$

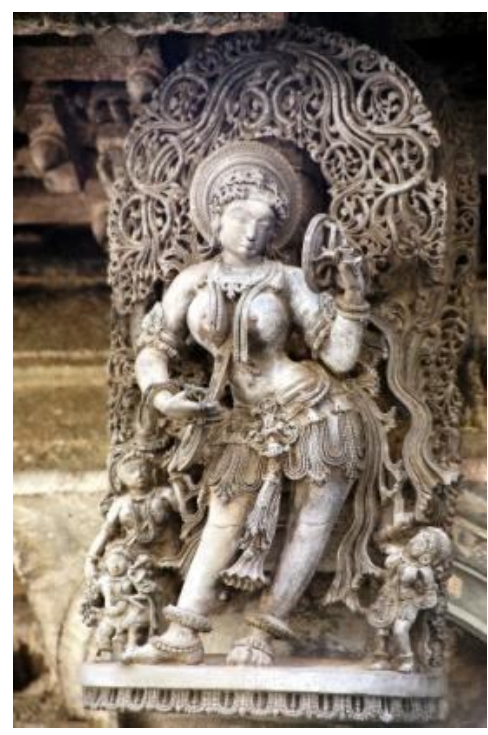

个Figure 26. DarpanaSundari Traditional Indian Sculpture.

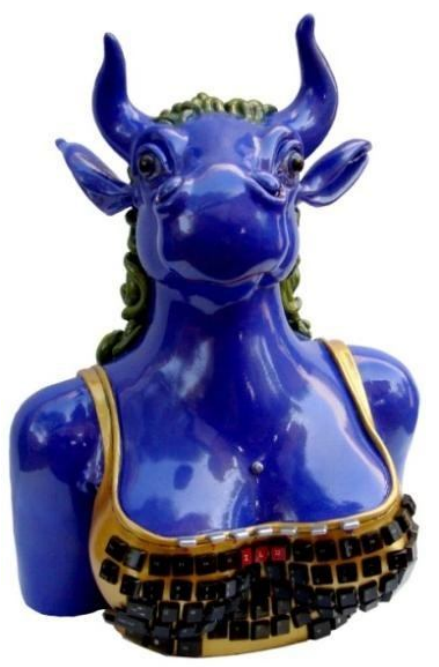




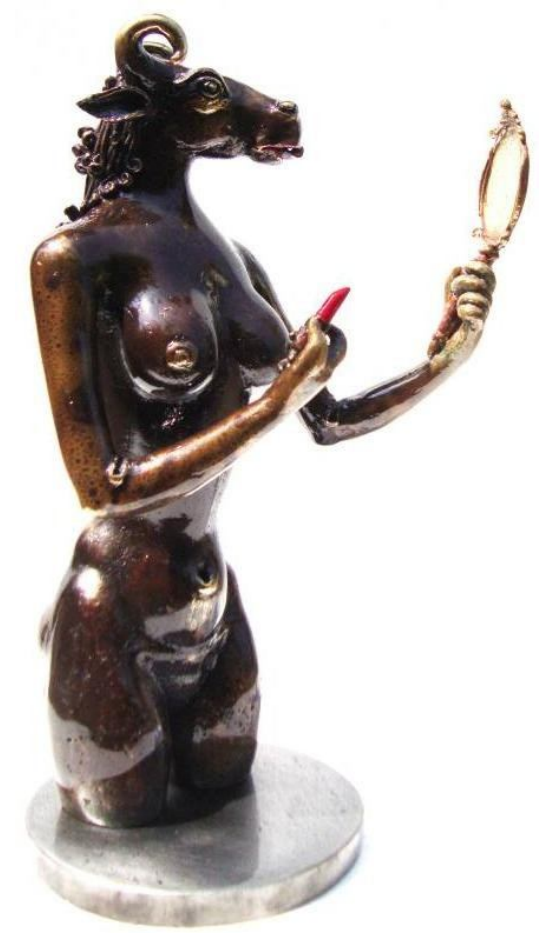

个Figure 30-31. (Darpana Sundari) Title- 'Passion of Fashion' material- Bronze size-
inches. $\rightarrow$

Darpana Sundari also evolved out of the popular traditional sculpture of women with a mirror in a feminine posture as you can see in 'fig no. 26 '.

In Srinivas Darpana Sundari Titled 'Passion of Fashion' the treatment of the form the female body is completely modern and realistic but at the same time

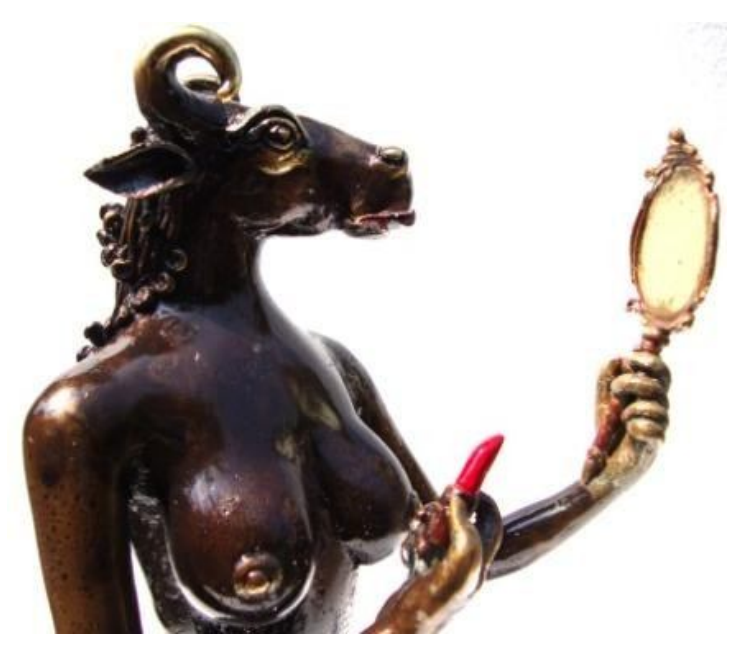
he tried to personalize the treatment of form and in applications. Unlike the traditional Darpana Sundari, he worked on the curves, the shape, the naked breasts the shoulder bones the neck and the abdomen in his own way, he says,

"Woman form is the most beautiful creation in the nature, I enjoy working the form, while sculpting applying each piece of wax and mending the curves with hands it is like touching and feeling the real women body. Every time the female body in my sculptures gets fine-tuned with this approach and every step the form transforms and changes in minute details."

In the face here one can see the depth in the eyes, shape is treated completely in a personalize manner simplified, eye ball he used his daughter soft toy eyes to give realistic look. The spiral form used for nostrils is unique completely his own, the nose, the jaws and the neck, it looks the artist has totally fallen in love with the woman body and it is visible in this work. 

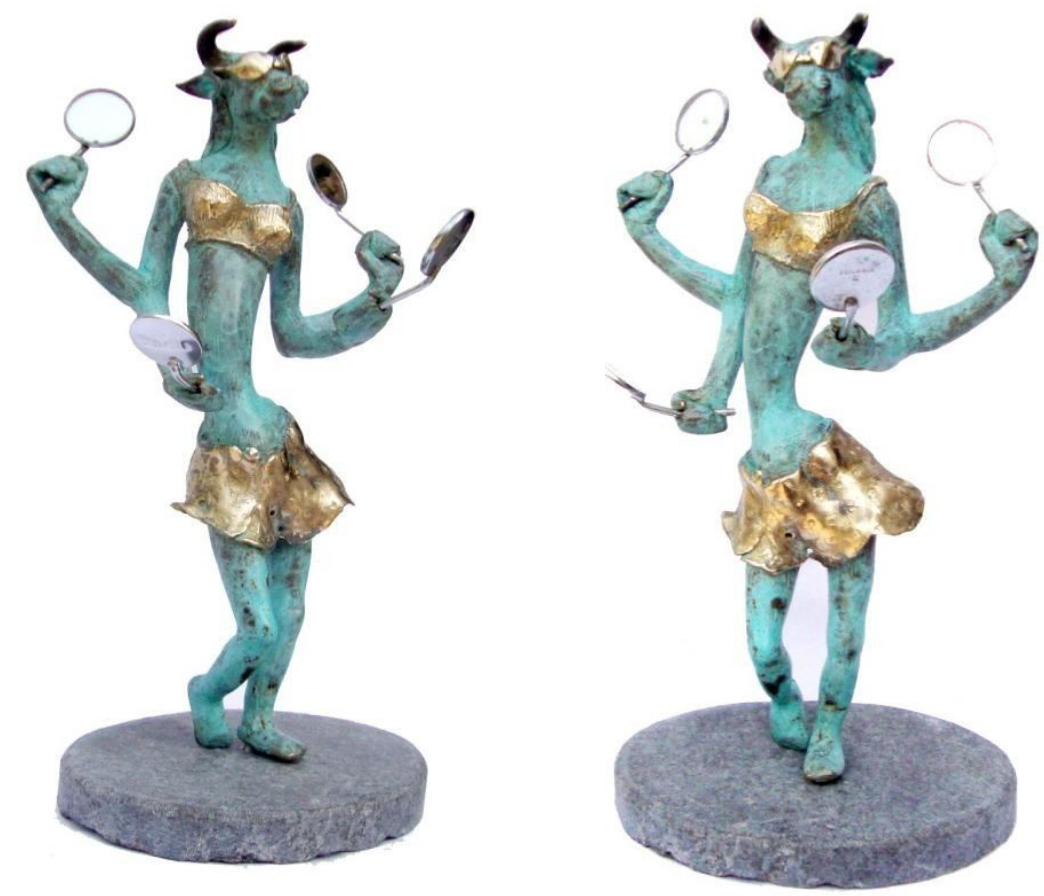

In the next level he gave 'Parahasthalu', many hands and all the hands holding the mirrors. Like the goddesses Durga, Chandi with many hands carrying different weapons, the many mirrors here is to show 'beauty' as the power or strength. A sense of pride in the face with all her innocence, the Female Figure is slim but very tough from inside. Here she looks in playful mode in a dancing posture, enjoying the momentum with all the mirrors in hand. We can feel the rhythm. Time space form is well - balanced.

个Figure 32-33. 'Darpan sundari I' medium-Bronze, steel, stone and mirror, Size- 11x6x4 inches.

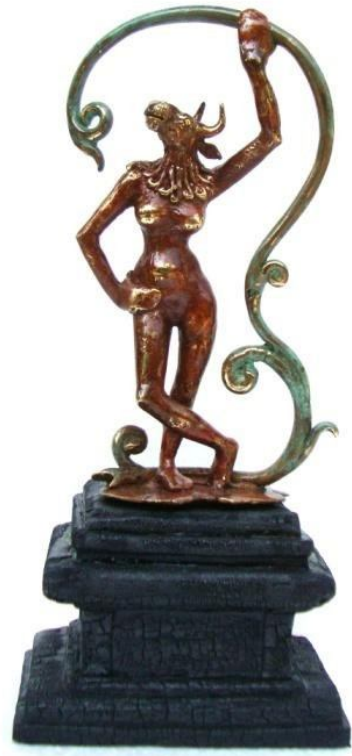

Figure 34. untitled-13x6x4-Bronze and Wood-2011 Here we can see Yakshini as 'Lathangi'.

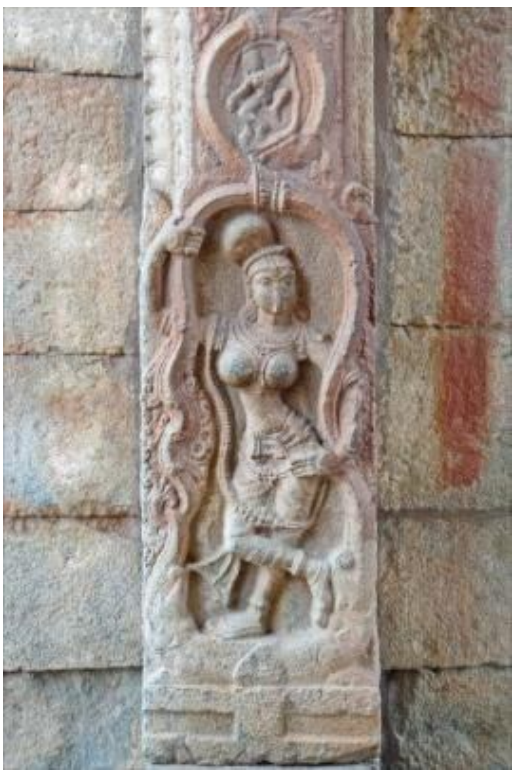

Figure35. Yakshi at Vittal Temple, Vittal Hampi Vijayanagar Karnataka. 
For Srinivas the process of work is very important, engaging with the form, building and developing it slowly with all intricacies and nuances without missing the expression and the main concept. He says, 'My work should also show the amount of work and the labor put into it'. The women in Betty style with bull head, the form has evolved with great interest in the beauty of women body, the curves the lines the flow but instead of showing delicacy and feminine I made the form strong, though slim. She holds all kinds of modern gadgets represent the modern day women, with sun glasses or goggles. Even in bronze we can feel the material of her cloths and the gadgets she holds and wear. He says 'one should feel the material not only of the sculpture made of but also of the concept'.

With his nature of constant experiments in work, the concepts and the forms are in regular transformations according to the need of his expressions.

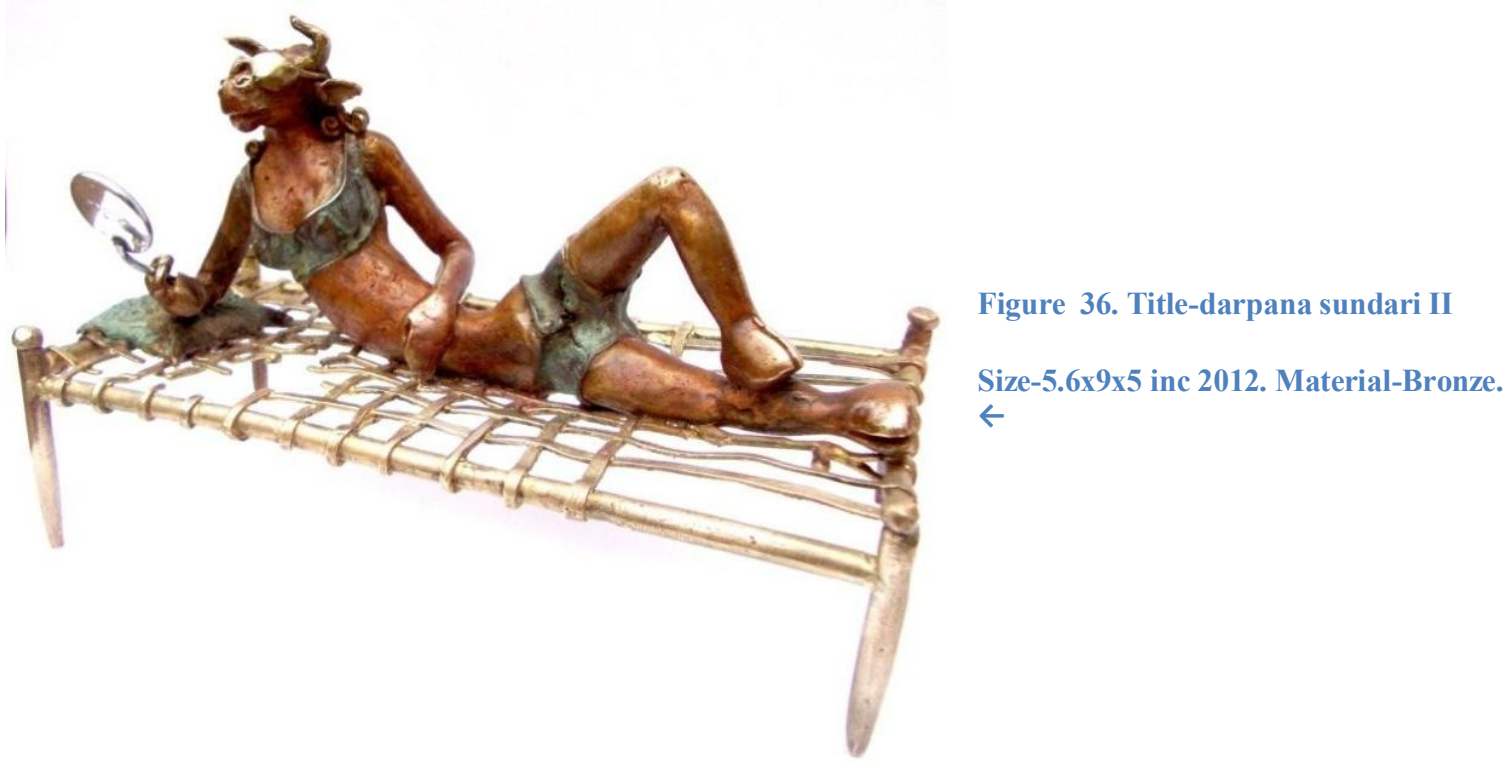

Here one can see the female figure in playful position on the traditional village cot and reading a book.

Figure 37.

Title-'Gallo telutu unde',

Medium-Gold plating and patina on bronze,

Size-11" X 14" X 8",

Year-2013. $\rightarrow$

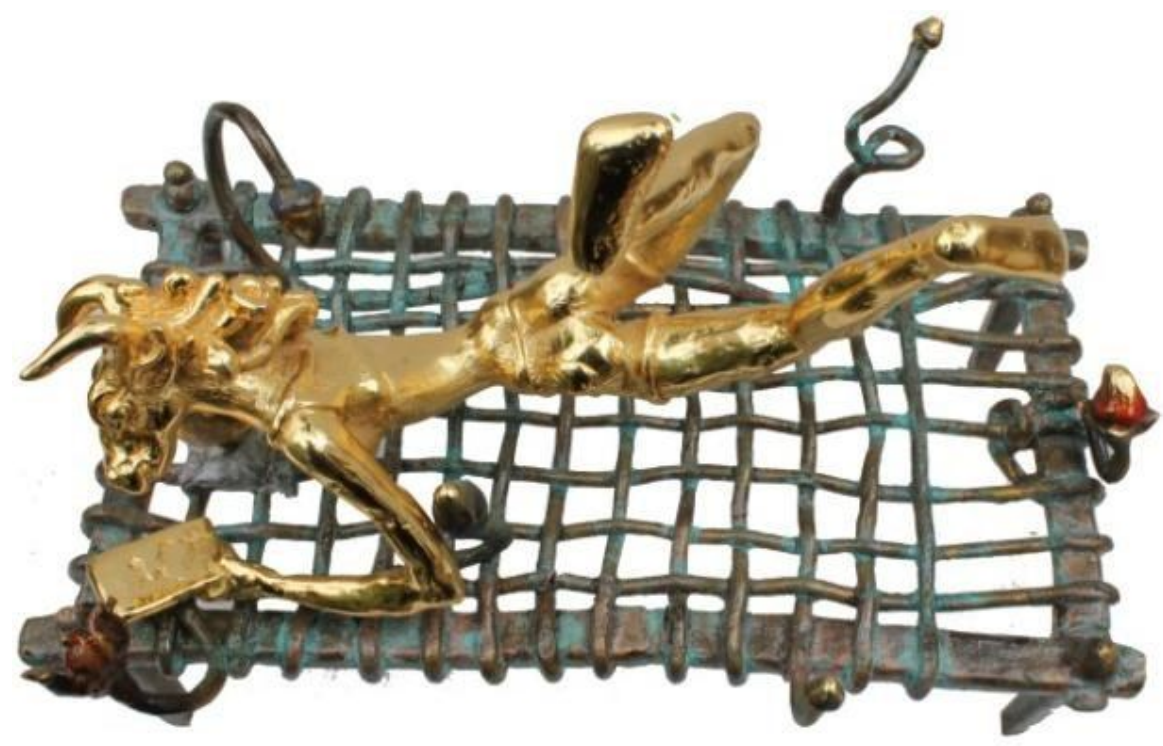




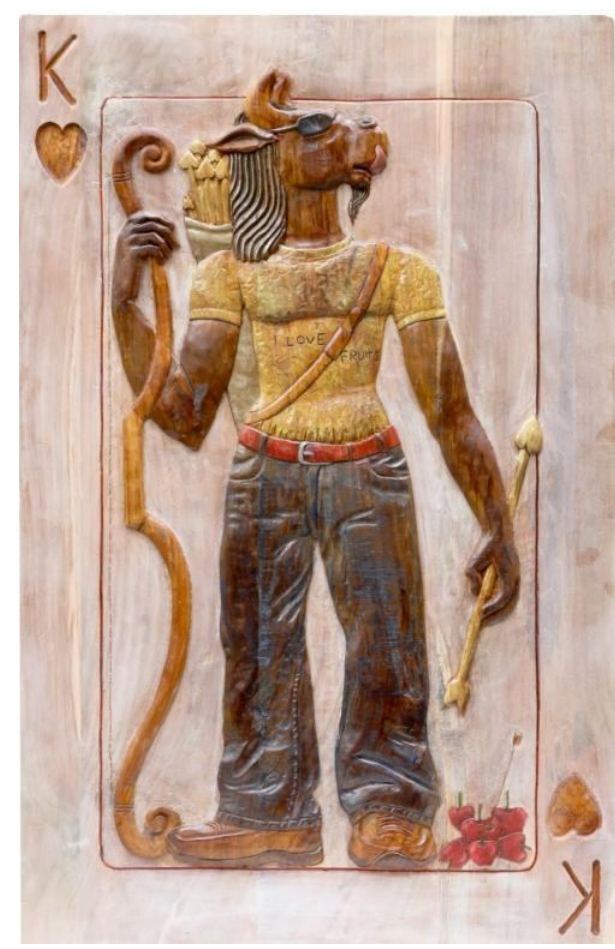

Fig.38.'King’, Medium- oil on teak wood (carving)-42x27in.

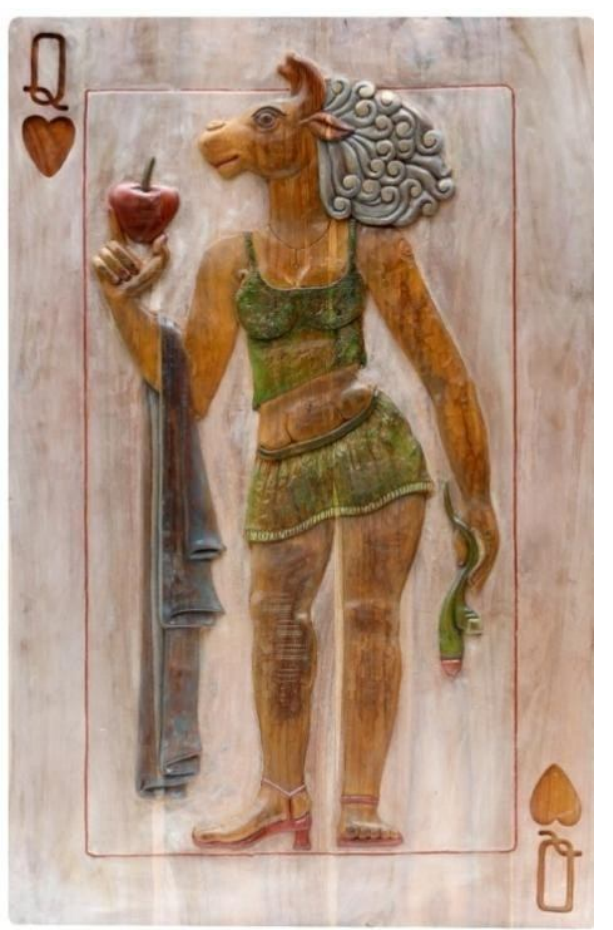

Fig.39. 'Queen'-oil on teak wood (carving)-42x27in-2013

The King and the Queen, in a remote way we can think of yaksha-yakshini, but the concept here is totally different the "king and queen" of the playing cards is a 'relief work' in Wood. Influenced by some western European sculptural reliefs he painted these with oil paints. The $K$ and $Q$, is about man women relationships the artists creative interventions can be seen in placing a 'Rama baan' from Hindu mythological character, the standing position of the King also reflects Ram. The bow and arrow in the hands of male and an apple in the hands of female symbolizes love gesture, the towel speaks consciousness of the beauty and care. The costumes are ultra modern and the bull head speaks the power, the animal instincts and nature of desires in human. The women already fallen for him is represented by showing some apple at his feet which speaks the men desires for women is never ending. He says,

"...when asked about the bow and arrow it has come naturally, I feel these kinds of elements come naturally in view of my educational and the cultural background I have come from. The Concept of $\mathrm{K}$ and $\mathrm{Q}$ came when I was playing cards with my wife."

Srinivas's is a love cum arranged marriage, his wife Ramya is a great moral support, and blessed with a charming daughter chaitu six yrs old, who practices sculpture with her father at his studio.

Figure 40. 'girl playing with bubbles' Medium-bronze Size-12x10x5 in,

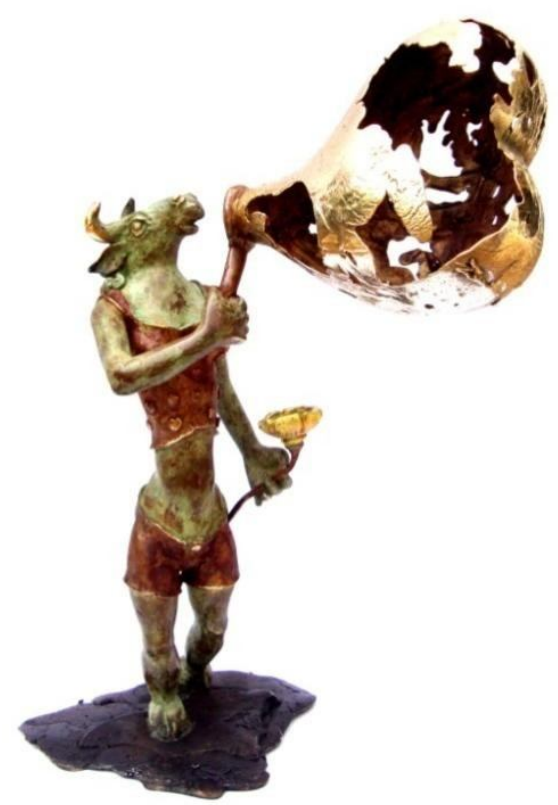


When we see Srinivas work in the current modern trend in India at national or international context, we can see some contemporary sculptors and conceptual artists have worked either using the traditional forms directly and presenting them with all the decorative patterns remains same, where we won't see the sculptor's sculpting activity like his, nor tried to personalize, or they added modern elements gadgets to the traditional sculptural forms. Some artist's works are the statements of the Indian village life style the direct usage of elements or the realistic replication in large scale the popular Indian images and concepts vintage elements were picked up especially in postmodern installations. Like a vintage vehicle converted in bronze as it is and placed in the gallery, there the artist is giving statement of culture. We won't see the artist's personal handwork in it. It's an 'idea a concept' for them. In Srinivas work we can see the bike- form completely different, though his also a popular company bike, he treats the form in his own way, a personal stylization of form is clearly seen in the work along with the sculpting process undergone while making.

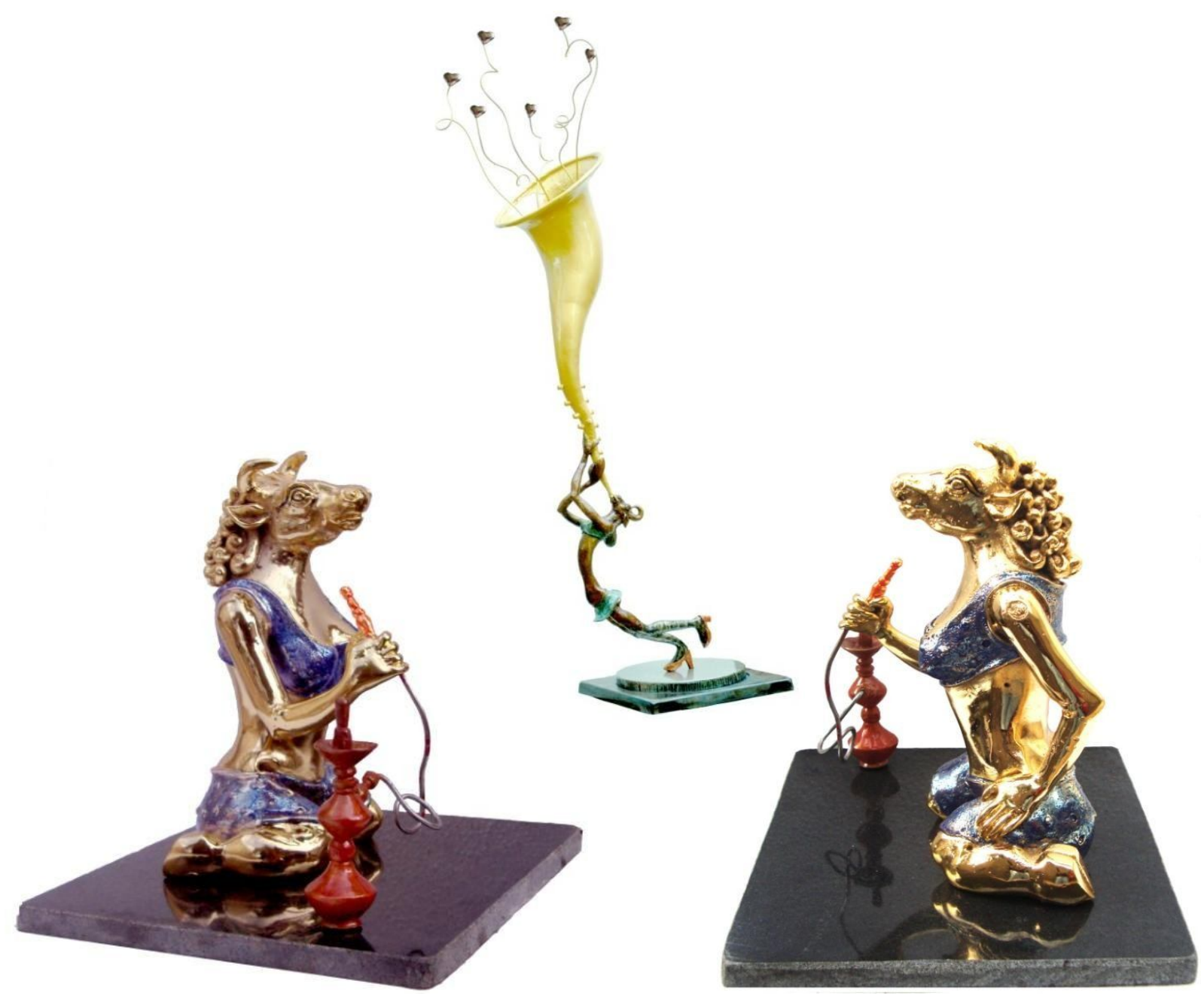

Figure 41. Title- 'love song' material-bronze, aluminum, iron and wood. Painted with Deco-

colors and steel plating, Size-50x18x12 inches -2013 .

Untitled, Material-gold plating and patina on bronze and stone-12x10x11 inch-2014. Figure 42-43. 
When it is about large scale, Srinivas worked sculptures up to ten feet height. But they were mostly steel and iron scrap, bonze is a costly affair so maximum height he worked are in 1.5 feet height and 3 feet in length, each piece of this size costs him Rs.40,000/-. Bronze is a huge investment, he says "but I will definitely go to large scale in bronze when an enthusiast sponsor art appreciator who would like to invest in my work.

"The bull, the bikes, the bull head, the man-women relationships

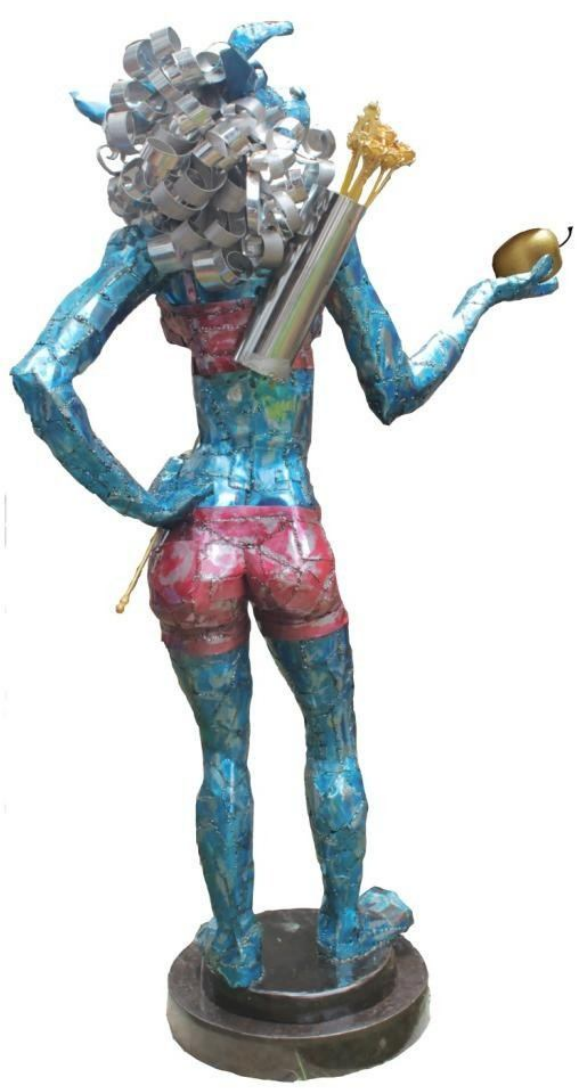
these are all the inside me, the man in me speaking through these forms, which represent the speed, the power, the vigor, the energy, the ego, the attitude, the man in me, simply to say 'the animal power inside $\mathrm{me}^{\prime}$ he emphasizes.

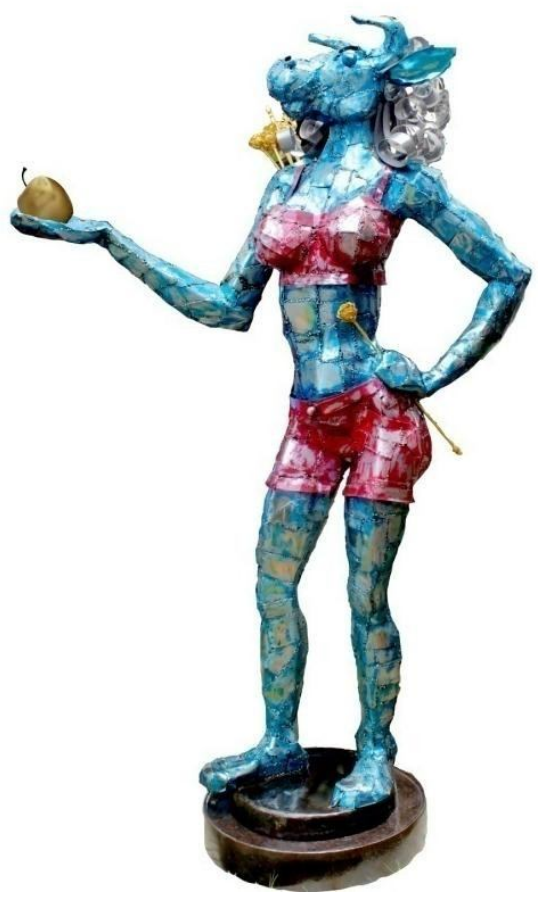

Figures 44, 45. 'blue girl', Medium-iron, stainless steel and aluminum and Deco- painting Size-90x52×25 inc-2013.

A New language he is speaking through his works. We can see clearly the sincere efforts of his expressions and forms. The maturity of form, rhythm, space, time plays vital roles in his work.

M.Srinivasa Rao is definitely a promising talent of India who will shine on the international platforms.

Figure 45. $\uparrow$

Each work of his speaks about his commitment towards work.

Nearly 20 new works are getting ready for a solo show he has plans for, all in his favorite medium, bronze.

Sculptor M.Srinivasa Rao, working at his shared-Studio in Hyderabad, Telangana.

Figure 46.

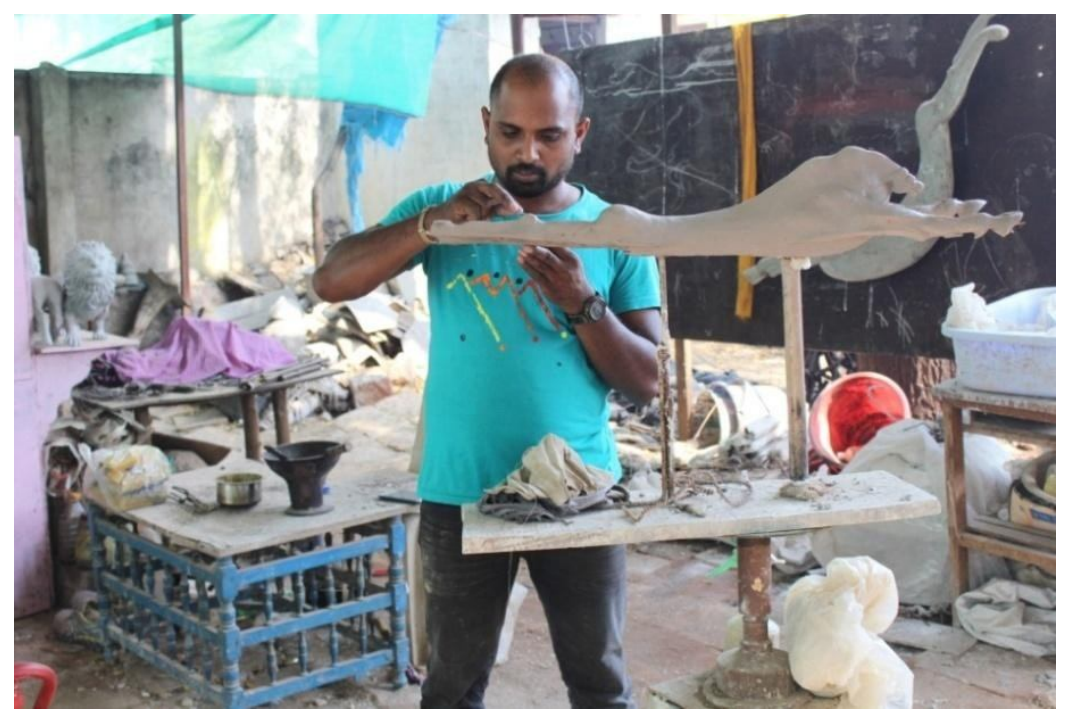

